\title{
Helicobacter Pylori Status in Explant Livers of Liver Transplant Recipients in a European Patient Cohort
}

\author{
Anna Hüsing1, Wolfgang Hartmann², Inga Grünewald ${ }^{2}$, Sameer Dhayat ${ }^{3}$, Jörg Haier ${ }^{3}$, Verena Böhmer ${ }^{4}$, \\ Gerold Thölking $^{5}$, Hartmut H Schmidt ${ }^{1}$, Tilmann Spieker ${ }^{6}$, Iyad Kabar ${ }^{1 *}$ \\ ${ }^{1}$ University Hospital Muenster, Department of Transplant Medicine, 48149 Muenster, Germany \\ ${ }^{2}$ University Hospital Muenster, Gerhard-Domagk-Institute of Pathology, 48149 Muenster, Germany \\ ${ }^{3}$ University Hospital Muenster, Department of General and Visceral Surgery, 48149 Muenster, Germany \\ ${ }^{4}$ Institute for Pathology, Klinikum Fulda gAG, Fulda, Germany \\ ${ }^{5}$ University Hospital of Münster, Department of Medicine D, Division of General Internal Medicine, Nephrology and Rheumatology, \\ 48149 Münster, Germany \\ ${ }^{6}$ Institute for Pathology at St. Franziskus-Hospital, Muenster, 48145 Muenster, Germany
}

*Corresponding Author: Iyad Kabar, MD, Department of Transplant Medicine, University Hospital Münster, Albert-Schweitzer-Campus 1, Gebäude A14, Muenster 48149, Germany, Tel: +49-251-8344957; Fax: +49-251-8357771; E-mail: iyad.kabar@ukmuenster.de

\section{Abstract}

\section{Background and study aims}

Helicobacter pylori (H. pylori) are known to be associated with several intestinal and extra-intestinal diseases such as peptic ulcers, mucosa-associated lymphoid tissue lymphoma, gastric cancer and/or idiopathic thrombocytopenic purpura. Recently, H. pylori genomic DNA has been detected in liver tissue of patients with chronic liver diseases. Furthermore, some studies suggested that detection of H. pylori is associated with progressive liver disease. However, the influence of this organism on the progression of chronic liver diseases remains unclear. The aim of this study was to evaluate the role of $H$. pylori in patients undergoing Liver Transplantation (LT) owing to end-stage liver disease.

\section{Patients and methods}

This retrospective study enrolled 50 explant liver tissue from consecutive patients undergoing LT at the University Hospital of Muenster between January 2011 and December 2012. H. pylori DNA was detected in specimens by PCR.

Results

We successfully extracted DNA from every liver tissue sample; however, $H$. pylori were not detectable in any liver specimen tested.

\section{Conclusion}

In our patient cohort, $H$. pylori were not detectable in explant liver. Based on these results, $H$. pylori do not appear to have a significant impact on the progression of liver disease in our patient cohort.
Received Date: March 15, 2017

Accepted Date: April 17, 2017

Published Date: April 22, 2017

Citation: Iyad Kabar., et al. Helicobacter Pylori Status in Explant Livers of Liver Transplant Recipients in a European Patient Cohort. (2017) J Gastrointest Disord Liver Func 3(1): 94- 97.

DOI: $10.15436 / 2471-0601.17 .1423$

Keywords: Helicobacter pylori; Liver tissue; Liver transplantation; Hepatocellular cancer, Liver diseases

\section{Introduction}

Helicobacter pylori (H. pylori) are a gram negative, spiral, microaerophilic bacterium, which infects more than $50 \%$ of human stomachs ${ }^{[1,2]}$. Infection with $H$. pylori plays a crucial role in the pathogenesis of several gastric disorders such as peptic ulcer disease, mucosa-associated lymphoid tissue lymphoma and gastric cancer. Elimination of this microorganism is therefore an important goal in the treatment and healing of these disorders ${ }^{[3,4]}$. Furthermore, H. pylori is also known to favour the emergence of extra-intestinal diseases such as hepatic encephalopathy ${ }^{[5]}$ and idiopathic thrombocytopenic purpura, sideropenic anemia, and 
vitamin $\mathrm{B}_{12}$ deficiency ${ }^{[6]}$. Additionally, $H$. pylori have also been considered as a potential trigger of autoimmune disorders ${ }^{[7]}$. In a recently published literature review, Feng et al., found a significantly high prevalence of $H$. pylori infection in patients with liver cirrhosis ${ }^{[8]}$. The same review showed that prevalence of this infection in patients with primary biliary or viral cirrhosis was higher compared with alcohol-induced cirrhosis of the liver. One study found an association between $H$. Pylori seropositivity and hepatocyte ballooning, suggesting that $H$. pylori infection may play a role in the progression of non-alcoholic fatty liver disease (NAFLD) to non-alcoholic steatohepatitis ${ }^{[9]}$. Other studies have also indicated that detection of H. pylori in liver tissue was associated with a higher incidence and progression of liver diseases such as Hepatocellular Carcinoma (HCC), hepatitis C-infection or autoimmune liver disorders ${ }^{[10]}$. A study from Nilsson et al., found that the detection of helicobacter is more frequent in the liver of patients with cholestatic liver diseases, compared with patients suffering from non-cholestatic diseases or healthy subjects $^{[11]}$. Therefore, in primary sclerosing cholangitis, $H$. pylori may play some role in the development and/or progression of the disease in certain patients ${ }^{[12]}$. Furthermore, H. pylori has also been reported to induce hepatotoxicity in vitro ${ }^{[13]}$.

Conversely, a study from Esmat et al., found no association between $H$. pylori DNA and quantitative hepatitis C virus RNA. Furthermore, no significant difference in Child-Pugh stage was found between the helicobacter PCR-positive group and the H. pylori-negative group ${ }^{[14]}$. A further study could not find any significant association between $H$. pylori infections and NAFLD ${ }^{[15]}$.

The aim of our study was to evaluate the prevalence of $H$. pylori in explant livers and the role of this microorganism in development and progression of liver disorders leading to endstage liver diseases in patients undergoing liver transplantation at our centre.

\section{Material and Methods}

In this retrospective study, we included consecutive patients who underwent LT between January 2011 and September 2012. DNA was extracted from formalin-fixed explant livers and was analysed to detect the presence of $H$. pylori-specific DNA. This study was conducted in accordance with the guidelines of the Declaration of Helsinki after consulting the local institution- al review board of the University of Münster.

\section{DNA extraction and PCR}

For DNA extraction from FFPET, $10 \mu \mathrm{M}$ sections were cut. After standard de-waxing and overnight Proteinase K digestion, DNA was extracted using a Qiacube instrument and recommended reagents (Qiagen, Hilden, Germany) following the manufacturer's instructions. Standard PCR (40 cycles) was performed in duplicate in a volume of $20 \mu \mathrm{l}$ with $100 \mathrm{ng}$ and $10 \mathrm{ng}$ of DNA as template and $2.8 \mathrm{pmol}$ of each primer. For $H$. pylori $16 \mathrm{~S}, 23 \mathrm{~S}$ and GyrA assays, a second round of nested PCR (20 cycles) employing $2 \mu \mathrm{l}$ of the first PCR product were performed to increase sensitivity and specificity. Primers used were:

$16 \mathrm{~S}: 5^{\prime}$ - ACGACAGCCGTGCAGCACC-3', 5 ' - GCTTAGTCTCTCCAGTAATGCAGCTAACG-3', nested: 5 ' - TGGCAAGCCAGACACTCCA-3', 5 ' - GCTTA G T C T C TCCAGTAAT GCAGCTAACG-3',23 S : 5' - CATAAGAGCCAAAGCCCTTACTTCAAAGC-3', $5^{\prime}$ - CCTTGTCGGTTAAATACCGACCTGC-3', nested:5' - CCTTACTTCAAAGCCTCCCACCTATCC-3', 5' -CCTTGTCGGTTAAATACCGACCTGC-3', GyrA: 5' -GCATGAATTAGGCCTTACTTCCAAAGTCG-3', 5'-GCCTTAGTCATTCTGGCTTCAGTGTAACG-3',nested:5'-GCATGAATTAGGCCTTACTTCCAAAGTCG-3', 5'-GCAGCGTTATCGCCATCAATAGAGC-3'.

Suitable positive and negative controls were included in each PCR assay. To confirm the integrity of the DNA, an additional beta-globin PCR was performed as described above using the primers 5'-GAAGAGCCAAGGACAGGTAC-3' and 5'-CAACTTCATCCACGTTCACC-3'. Products were analysed on $2 \%$ agarose gels with expected sizes of $200 \mathrm{bp}$ (16S), $201 \mathrm{bp}$ (23S), 198 bp (GyrA), and 268 bp (beta-globin). PCR products were analysed by Sanger Sequencing.

To determine the sensitivity of the assay, we included a titration experiment with a positive control of $H$. pylori infected gastric mucosa with a (total) DNA concentration of 31 $\mathrm{ng} / \mu \mathrm{l}$. The sample was serially diluted 1:5 in five steps, i.e. the final range of DNA concentration employed as template in the PCR assays was $31 \mathrm{ng} / \mu 1-0.01 \mathrm{ng} / \mu \mathrm{l}$. PCRs were performed in a nested approach as described above. The detection limit of H. pylori after two rounds of PCR was $0.05 \mathrm{ng} / \mu \mathrm{l}$ (total DNA concentration). Figure 1 show testing of sensitivity of $H$. pylori PCRs.

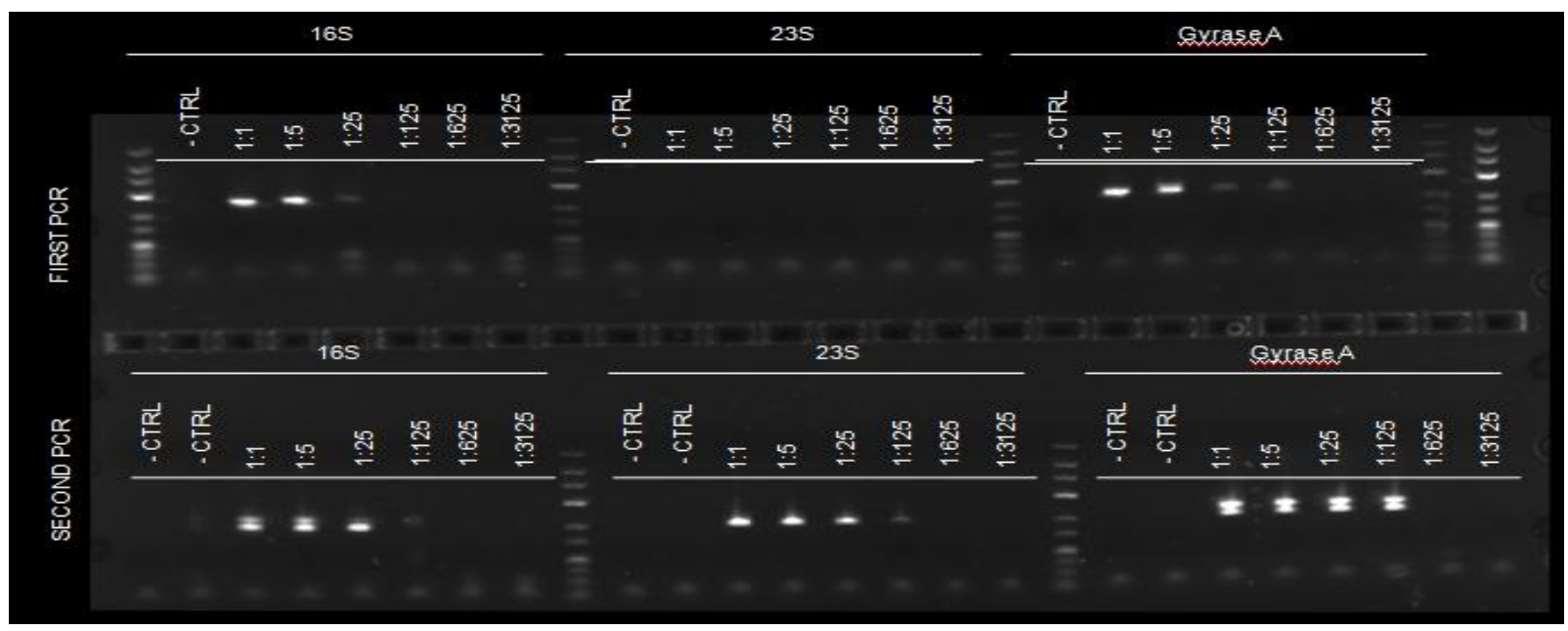

Figure 1: Testing of sensitivity of $H$. pylori PCRs. 


\section{Results and Discussion}

A total of 50 explant livers fixed in formalin and embedded in paraffin wax, were included in the study. The mean age of patients at the time of transplantation was $50.8 \pm 11.1$ years; range, $24-73$ years. The most common diagnosis leading to LT was HCC, followed by alcoholism and chronic viral hepatitis. Clinical data and demographic characteristics of patients are shown in Table 1. Following PCR analysis, no H. pylori-specific DNA was detectable in the liver tissue from any of our 50 patients. All patients underwent gastroscopy during their clinical course, with 45 also undergoing gastric tissue biopsy. Four of the 45 patients with biopsy material were PCR-positive for H. pylori, three of which were detected prior to LT and therefore received helicobacter eradication treatment, while infection in the fourth patient was detected after transplantation. Multiple studies have implicated $H$. pylori in the development and/or worsening of several liver diseases. However, the role of this infection as a risk factor in the pathogenesis and progression of liver disorders is still controversial. Since there is evidence that H. pylori DNA can be isolated from formalin-fixed paraffin-embedded liver tissue (FFPET) ${ }^{[16,17]}$, we consecutively analysed explant livers of patients who underwent LT during the time under consideration. In each case, we were able to isolate DNA from FFPET. However, H. pylori DNA could not be detected in any of the cases in our study population. Our results suggest that this microorganism does not play any decisive role in the pathogenesis and progression of liver disease in our western European patient cohort. An explanation for this finding may be the low prevalence of $H$. pylori infection in the study population. Only four of the 45 patients $(8.9 \%)$ who underwent gastroscopy with biopsy during their clinical course were positive for $H$. pylori. This result is consistent with the increasing evidence showing a significant and quick decrease of $H$. pylori prevalence in Northern European countries, whereas the prevalence of $H$. pylori in Southern Europe (for example, in Turkey and in Portugal) and in Asian and African countries still remains very high ${ }^{[18,19]}$. Thus, it is not surprising that much of the data showing $H$. pylori to be a significant influence on the course of liver diseases have come from Asia, Southern Europe and Egypt, where the prevalence of infection is known to be high ${ }^{[5,20]}$.

Table 1: Clinical Data.

\begin{tabular}{|l|c|}
\hline Mean age & $50.8 \pm 11.1$ \\
\hline Male/female & M: $31(62 \%)$ \\
F: $19(38 \%)$
\end{tabular}

* Some patients presented with more than one diagnosis

\section{Conclusion}

H. pylori infection does not seem to play a decisive role in the development and progression of chronic liver disorders in a Western European patient cohort. This fact may be because of the low prevalence of $H$. pylori in this study population. Further multicenter studies, encompassing different ethnic and geographical cohorts, are important for evaluation of the true role played by this bacterium in liver diseases.

\section{Conflicts of Interest}

The authors declare that there are no conflicts of interest.

\section{Acknowledgements}

This study was supported by the Department of Transplant Medicine and the Gerhard-Domagk-Institute of Pathology of the University Hospital Muenster. No external funding was received. 


\section{References:}

1. Sakr, S.A., Badrah, G.A., Sheir, R.A. Histological and histochemical alterations in liver of chronic hepatitis $\mathrm{C}$ patients with Helicobacter pylori infection. (2013) Biomed Pharmacother 67(5): S367-S374.

Pubmed | Crossref| Others

2. Eusebi, L.H., Zagari, R.M., Bazzoli, F. Epidemiology of Helicobacter pylori infection. (2014) Helicobacter 19(1): S1-S5.

Pubmed|Crossref|Others

3. Fischbach, W. Gastric MALT lymphoma - update on diagnosis and treatment. (2014) Best Pract Res Clin Gastroenterol 28(6): S1069-S1077.

Pubmed | Crossref| Others

4. Megraud, F., Bessede, E., Varon, C. Helicobacter pylori infection and gastric carcinoma. (2015) Clin Microbiol Infect 21(11): S984-S990.

Pubmed | Others

5. Karahalil, B., Yagar, S., Ozin, Y. Release of alpha-glutathione S-transferase (alpha-GST) and hepatocellular damage induced by Helicobacter pylori and eradication treatment. (2007) Curr drug safe 2(1): S43-S46.

Pubmed |Crossref $\mid$ Others

6. Franceschi, F., Tortora, A., Gasbarrini, G., et al. Helicobacter pylori and extragastric diseases. (2014) Helicobacter 19(1): S52-S58.

Pubmed|Crossref|Others

7. Smyk, DS., Koutsoumpas, AL., Mytilinaiou, MG., et al. Helicobacter pylori and autoimmune disease: cause or bystander. (2014) World J Gastroenterol 20(3): S613-S629.

Pubmed | Crossref| Others

8. Feng, H., Zhou, X., Zhang, G. Association between cirrhosis and $\mathrm{He}-$ licobacter pylori infection: a meta-analysis. (2014) Eur J Gastroenterol Hepatol 26(12): S1309-S1319.

Pubmed | Crossref| Others

9. Sumida, Y., Kanemasa, K., Imai, S., et al. Helicobacter pylori infection might have a potential role in hepatocyte ballooning in nonalcoholic fatty liver disease. (2015) J Gastroenterol Pubmed| Others 50(9): S996-S1004.

10. Pellicano, R., Menard, A., Rizzetto, M., et al. Helicobacter species and liver diseases: association or causation? (2008) Lancet Infect Dis 8(4): S254-S260.

Pubmed | Crossref | Others

11. Nilsson, HO., Taneera, J., Castedal, M., et al. Identification of Helicobacter pylori and other Helicobacter species by PCR, hybridization, and partial DNA sequencing in human liver samples from patients with primary sclerosing cholangitis or primary biliary cirrhosis. (2000) J Clin Microbiol 38(3): S1072-S1076.

Pubmed|Others
12. Krasinskas, AM., Yao, Y., Randhawa, P., et al. Helicobacter pylori may play a contributory role in the pathogenesis of primary sclerosing cholangitis. (2007) Dig Dis Sci 52(9): S2265-S2270.

Pubmed|Crossref|Others

13. Taylor, NS., Fox, JG., Yan, L. In-vitro hepatotoxic factor in Helicobacter hepaticus, H. pylori and other Helicobacter species. (1995) J Med Microbiol 42(1): S48-S52.

Pubmed | Crossref| Others

14. Esmat, G., El-Bendary, M., Zakarya, S., et al. Role of Helicobacter pylori in patients with HCV-related chronic hepatitis and cirrhosis with or without hepatocellular carcinoma: possible association with disease progression. (2012) J Viral Hepat 19(7): S473-S479.

Pubmed |Crossref |Others

15. Okushin, K., Takahashi, Y., Yamamichi, N., et al. Helicobacter pylori infection is not associated with fatty liver disease including non-alcoholic fatty liver disease: a large-scale cross-sectional study in Japan. (2015) BMC Gastroenterol 15: S25.

Pubmed |Crossref | Others

16. Rabelo-Goncalves, E., Roesler, B., Guardia, AC., et al. Evaluation of five DNA extraction methods for detection of $H$. pylori in formalin-fixed paraffin-embedded (FFPE) liver tissue from patients with hepatocellular carcinoma. (2014) Pathol Res Pract 210(3): S142-S146. Pubmed|Crossref|Others

17. Rabelo-Goncalves, EM., Sgardioli, IC., Lopes-Cendes, I., et al. Improved detection of Helicobacter pylori DNA in formalin-fixed paraffin-embedded (FFPE) tissue of patients with hepatocellular carcinoma using laser capture microdissection (LCM). (2013) Helicobacter 18(3): S244-S245.

Pubmed | Crossref| Others

18. Hunt, RH., Xiao, SD., Megraud, F., et al. Helicobacter pylori in developing countries. World Gastroenterology Organisation Global Guideline. (2011) J Gastrointestin Liver Dis 20(3): S299-S304.

Pubmed | Others

19. Eusebi, LH., Zagari, RM., Bazzoli, F. Epidemiology of Helicobacter pylori infection. (2014) Helicobacter 19(1): S1-S5.

Pubmed | Crossref | Others

20. Sakr, SA., Badrah, GA., Sheir, RA. Histological and histochemical alterations in liver of chronic hepatitis $\mathrm{C}$ patients with Helicobacter pylori infection. (2013) Biomed pharmacother 67(5): S367-S374.

Pubmed | Crossref| Others

\section{Ommega Publisher}

Journal Title: Journal of Gastrointestinal Disorder \& Liver Function (JGDLF)

Short name: J Gastro Dis Liver Func
ISSN No: 2471-0601

E-Mail Id: gastrology@ommegaonline.com

Website: www.ommegaonline.org 